\title{
El empleo digno de las personas transexuales en Cuba. Análisis a la luz de la nueva Constitución de la República de Cuba
}

Decent employment of transgender people in Cuba. Analysis in light of the new Constitution of the Republic of Cuba

\author{
Dailién Portuondo del Pino. ${ }^{1} \&$ Lic. Reynaldo Lam Peña. ${ }^{2}$
}

Resumen.

DOI: https://doi.org/10.33262/concienciadigital.v2i4.850

El reconocimiento del derecho al empleo digno y la igualdad ante la ley de todas las personas en la nueva Constitución de la República de Cuba, llama a la reformulación normativa en materia laboral en pos de garantizar el ejercicio pleno de este derecho sin discriminación por identidad de género en las personas transexuales. Objetivo. Analizar desde la regulación constitucional, los elementos necesarios para garantizar el pleno acceso al empleo digno de las personas transexuales en Cuba. Metodología. Fueron utilizados distintos métodos investigativos. El método empírico de análisis de documentos, el método teórico jurídico-doctrinal y como técnica de investigación la revisión de documentos. Principales resultados. El derecho al trabajo está reconocido constitucionalmente en Cuba y encuentra pórtico en la dignidad humana. La aparición en el texto constitucional cubano del término "empleo digno" llama a garantizar su disfrute por todos los ciudadanos sin discriminación por identidad de género. Esta nueva concepción necesita de modificaciones normativas en el ámbito laboral y la generación de políticas públicas transversales en materia de género que contribuyan al desarrollo del mandato constitucional.

\footnotetext{
${ }^{1}$ Universidad de La Habana, La Habana, Cuba. dportuondo@gmail.com

${ }^{2}$ Universidad de La Habana. La Habana, Cuba. rlampena@gmail.com
} 
Palabras claves: trabajo digno, Constitución, derecho, identidad de género, transexuales.

\section{Abstract.}

The recognition of the right to a suitable employment and the equality in front of the law of all people in the New Constitution of the Republic of Cuba invokes to the normative reformulation in labour matter in order to guarantee the full exercise of this right without discrimination by the identity genre in transsexual persons. Objective. Analyze since the Constitutional Regulations the necessary elements to guarantee the full access to a suitable employment of transsexual persons in Cuba. Methodology. There were used several methods of investigation: empirical method, analysis of document, theoretic juridical- doctrine and as a technique of the investigation review of the documents. Main results. The right to work is constitutionally recognized in Cuba and finds entrance in the human dignity. The apparition in the Cuban Constitutional text of the term "suitable employment" calls to guarantee its enjoyment by all citizens without any discrimination by identity of genre. This new conception needs standard modifications in the compass of work and the generation of transversal public policies in matter of genre which contribute to the development of constitutional mandate.

Keywords: suitable employment, Constitution, right, identity genre, transexual.

\section{Introducción.}

De la lectura de la nueva Carta Magna proclamada el 10 de abril del presente año ${ }^{3}$, sobresalen cuestiones fundamentales entre las que se destaca, el desarrollo de una gama de derechos a tono con los instrumentos internacionales de los que Cuba es parte ${ }^{4}$. Entre los derechos regulados y reformulados se encuentra el derecho al trabajo ${ }^{5}$ y otros derechos en el trabajo, lo que le impone nuevos retos a esta disciplina.

En materia de derechos, constituye uno de los cambios fundamentales, el reconocimiento de la dignidad humana como derecho y como valor supremo ${ }^{6}$. La dignidad del ser humano es una condición que este tiene intrínseca por el hecho de ser tal; por tanto al cualificarlo debe

\footnotetext{
${ }^{3}$ Vid. Constitución de la República de Cuba, en Gaceta Oficial Extraordinaria No. 5 de 2019.

${ }^{4}$ Dentro de ellos se incluyen los Convenios de la Organización Internacional del Trabajo-organismo especializado de las Naciones Unidas que se ocupa de los asuntos relativos al trabajo y las relaciones laboralesemitidos para adecuar y lograr una uniformidad en este ámbito y que Cuba como miembro fundador ha ratificado.

${ }^{5}$ Vid. Artículo 64 de la Constitución de la República de Cuba aprobada el 22 de diciembre de 2018 en el Segundo Período Ordinario de Sesiones de la 9na. Legislatura de la Asamblea Nacional del Poder Popular y ratificada en Referéndum Popular el 24 de febrero de 2019.

6 Vid. Artículo 40 de la Constitución de la República.
} 
ser irrenunciable, inalienable, así como asegurada, respetada, promovida y garantizada por el Ordenamiento Jurídico estatal e internacional ${ }^{7}$. Se le atribuye a este derecho la condición de ser fuente, fundamento, base sustantiva, y condición de legitimación ${ }^{8}$ de todos los derechos fundamentales, pues todos van a contribuir a desarrollar un ámbito propio de la dignidad humana9; de ahí que su reconocimiento en la nueva Constitución de la República de Cuba, signifique que debe irradiar tanto a la norma de mayor jerarquía como a todo el sistema jurídico, el cual debe interpretarse y aplicarse conforme a las condiciones para que dicha dignidad se realice de la mejor forma ${ }^{10}$.

También adquiere un mayor desarrollo y alcance el derecho a la igualdad. Que se incorpore a los motivos de discriminación ya existentes que lo vulneran (color de la piel, sexo, raza, origen nacional, creencias religiosas y cualquier otra, lesiva a la dignidad humana) ${ }^{11}$, la no discriminación por orientación sexual, discapacidad, género, identidad de género, origen étnico o territorial ${ }^{12}$; va a permitir que tenga más contenido la prohibición constitucional de toda forma de discriminación nociva a la dignidad de las personas y que por ende atente contra la equidad y justicia social.

Específicamente lo relativo a la incorporación en la Constitución de las nociones de género e identidad de género, responde a la necesidad de darle protección legal a un grupo poblacional del país, pues de la existencia de esta diversidad de identidades, se hace necesario la aceptación de las diferencias y el reconocimiento social y respeto de las personas que no se ajusten a los esquemas del binarismo del sexo-género hasta hace pocos años predominantes, dentro de las cuales se encuentran las personas transexuales. En las condiciones de la sociedad cubana actual, la problemática de la transexualidad, de la integración social de las personas transexuales y del ejercicio pleno de sus derechos ha desbordado el ámbito de lo estrictamente personal, familiar y médico, y se está configurando como objeto que reclama una intervención social ${ }^{13}$, de ahí que le concierne al Estado y a otros organismos e instituciones sociales intervenir en los espacios de este grupo,

\footnotetext{
${ }^{7}$ Cfr. Nogueira Alcalá, Humberto; Dignidad de la persona, derechos fundamentales y bloque constitucional de derechos: una aproximación desde Chile y América Latina; Revista de Derecho 05/ 2010; Universidad Católica de Uruguay; p. 81 y ss.; 2010.

${ }^{8}$ Cfr. BATISTA TORRES, Jennifer; Derechos humanos y derechos fundamentales. Algunos comentarios doctrinales; IUS Labor 2/2018; p. 197.

${ }^{9}$ Cfr. Nogueira AlCALÁ, Humberto; Dignidad de la persona...; Ob. cit.86.

${ }^{10}$ Ídem.; p. 82.

${ }^{11}$ Vid. Artículo 42 Constitución de la República de Cuba, reformada el 26 de junio de 2002, publicada en la Gaceta Oficial de la República Edición Extraordinaria No.10 de 16 de julio de 2002.

${ }^{12}$ Vid. Título V: Derechos, Deberes y Garantías; Capítulo I: Disposiciones Generales; Artículo 42 de la nueva Constitución de la República de Cuba.

${ }^{13}$ Cfr. CASTRO ESPín, Mariela: "Estrategia para la integración social de las personas transexuales en el contexto actual de la sociedad cubana."; Tesis en opción al Grado Científico de Doctora en Ciencias Sociológicas; Facultad de Filosofía e Historia, Departamento de Sociología; Universidad de la Habana; La Habana; 2014; p.15.
} 
estimulando su participación social y ofreciendo soluciones de apoyo por medio de políticas sociales, mecanismos legales y jurídicos, instituciones y prácticas concretas ${ }^{14}$.

Las personas transexuales, se separan del binarismo del género socialmente aceptado, al no percibirse dentro de lo que se espera del sexo que se les asignó al nacer. Ello ha dado lugar a que algunas personas vean a la transexualidad como una desviación social o como un fenómeno anormal y que tengan sentimientos de transfobia ${ }^{15}$, la cual lleva generalmente a la discriminación y exclusión de las personas transexuales en distintos ámbitos de la vida.

En nuestro país a pesar de que es loable el esfuerzo realizado por las organizaciones e instituciones ${ }^{16}$ para brindar una protección a las personas transexuales, así como la voluntad de reconocer constitucionalmente el derecho a la igualdad de todas las personas y la no discriminación por motivo del género e identidad de género; la sociedad no ha logrado zafarse completamente de las raíces conservadoras que la ha caracterizado a lo largo de la historia, y ello tiene en determinadas ocasiones expresión en las relaciones en las que intervienen las personas transgéneros, se dan en determinados casos situaciones de exclusión y discriminación.

Como consecuencia de esa concepción, se dan también en el ámbito laboral estas situaciones de discriminación y exclusión hacia las personas transexuales (desde el instante de la adquisición de un puesto de trabajo hasta el momento en que se encuentran dentro del mismo), limitándoseles con ello la posibilidad de trabajar, de ver satisfechas mediante la realización del trabajo sus necesidades humanas individuales y familiares; así como su desarrollo personal y su aceptación e integración social.

Cuando suceden en Cuba estas situaciones en el ámbito laboral, a pesar de tener las personas transexuales, personalidad y capacidad jurídica laboral, se les vulnera un derecho reconocido constitucionalmente, pues el trabajo en una sociedad socialista como la nuestra además de ser el valor primordial, constituye, un derecho, un deber social y un motivo de honor de todas las personas en condiciones de trabajar ${ }^{17}$. Por ello el Derecho del Trabajo tiene un papel esencial, pues derivado tanto del principio protector como de su finalidad protectora se desprende la necesidad de que sea protegido el trabajador sin discriminación debido a su identidad de género, como parte débil de la relación laboral, lo que justifica que la intervención estatal no debe limitarse a la emisión de las normas y modificación de las

\footnotetext{
14 Ídem.; p.61.

${ }^{15}$ Se utilizan con frecuencia los términos transfobia o fobia de género para referirse a la discriminación específica hacia las personas transexuales. Cfr. CASTRO ESPíN, Mariela: "Estrategia para la integración social..."; Ob.cit; p.11.

${ }^{16}$ Dentro de las que se destaca el Centro Nacional de Educación Sexual(CENESEX), institución docente, investigativa y asistencial, en el área de la sexualidad humana. Vid. Sitio Web Centro Nacional de Educación Sexual. Disponible en www.cenesex.org.

17 Vid. Artículo 31 de la Constitución de la República de Cuba.
} 
existentes, pues debe comprender además la vigilancia de su cumplimiento efectivo y en su aplicación específica.

\section{Derecho al trabajo como derecho fundamental.}

Se considera al trabajo como un derecho humano fundamental; humano toda vez que va a ser titular de él toda persona por el simple hecho de su condición humana, al tener tal condición el derecho al trabajo, el Estado está en la obligación de respetarlo, promoverlo y garantizarlo; y fundamental, pues a partir de su constitucionalización, va a ser garantía de libertad, igualdad y dignidad (que sea mínimamente aceptable, tanto por sus condiciones como por su remuneración $^{18}$ ) y tener ante su vulneración un mecanismo para su defensa. Como características de los derechos humanos y fundamentales pueden señalarse la universalidad, la imprescriptibilidad, la inalienabilidad, la irrenunciabilidad, la inviolabilidad, la efectividad, la indisponibilidad, la interdependencia, la intransmisibilidad y la complementariedad.

Al permitir el trabajo satisfacer las necesidades tanto de los trabajadores como de sus familiares, el Derecho se coloca como herramienta para que ello se cumpla en condiciones saludables para el trabajador ${ }^{19}$. Es entonces derecho al trabajo -o a trabajar-, la prerrogativa que tienen los sujetos con personalidad jurídica para realizar una labor, -en condiciones dignas- con el fin de satisfacer sus necesidades; así como la posibilidad de percibir que sus Estados realizan esfuerzos para la promoción de empleos y políticas públicas en aras de su protección y promoción. Significa pues tener acceso a un empleo o a la posibilidad de realizar un trabajo para satisfacer necesidades personales, familiares o sociales. ${ }^{20}$

\section{Regulación cubana del derecho al trabajo como derecho fundamental}

En la Constitución de la República, el derecho al trabajo, encuentra regulación en el Artículo 64. Desde el primer artículo de la Carta Magna, se vislumbra que nuestra República se encuentra fundada en el trabajo. Tiene reconocimiento en el Título II referido a los Fundamentos Económicos, específicamente en el Artículo 31, el trabajo como derecho, valor, deber y motivo de honor; así como de fuente principal de ingresos que sustenta las condiciones de vida dignas, y permite elevar el bienestar material y espiritual y la realización de los proyectos individuales, colectivos y sociales, esto se debe al papel del trabajo en la sociedad socialista cubana.

\footnotetext{
18 Cfr. SIEGEL, Richard: "Hacia la formulación de una observación general sobre el derecho a trabajar: elementos básicos"; Documento informativo presentado al Comité de Derechos Económicos, Sociales y Culturales el día de debate general sobre el artículo 6 del Pacto, 24 de noviembre de 2003, p.4.

${ }^{19}$ Cfr. BATISTA TORRES, Jennifer: "El derecho al trabajo en el marco constitucional cubano"; Tesis en opción al título de Máster en Derecho Constitucional y Administrativo; Facultad de Derecho de la Universidad de la Habana, Departamento de Estudios Jurídicos Básicos; La Habana; 2018; p.43.

${ }^{20}$ Ibídem; p.44.
} 
El reconocimiento de la igualdad ante la ley de todas las personas, y en virtud de ella, el reconocimiento de que gozan de los mismos derechos, libertades y oportunidades, sin ningún tipo de discriminación (incluida por identidad de género) ${ }^{21}$, así como que sea uno de los fines del Estado garantizar la igualdad efectiva en el disfrute y el ejercicio de los derechos ${ }^{22}$; tiene trascendencia para el ámbito laboral, pues esa igualdad de derechos se extiende al derecho al trabajo.

Sin embargo, el derecho al trabajo como derecho fundamental y la posibilidad de disfrutar de ese derecho en virtud de la igualdad reconocida a todas las personas puede encontrarse limitado, por los derechos de los demás, la seguridad colectiva, el bienestar general, el respeto al orden público, la Constitución y las leyes ${ }^{23}$.

Una novedad en materia laboral es el reconocimiento en la Constitución ${ }^{24}$ de la posibilidad que tiene la persona en condición de trabajar de tener el derecho a obtener un empleo digno, en correspondencia con su elección, calificación, aptitud y exigencias de la economía y la sociedad.

\section{El empleo digno ${ }^{25}$ hacia una conceptualización y su regulación en Cuba}

Este término que en el contexto internacional ha sido reconocido como trabajo decente o trabajo digno ${ }^{26}$, puede ser visto como un objetivo o propósito ajeno a un determinado contenido técnico, también puede presentarse como un concepto integratorio que involucra y articula diversos objetivos, valores y políticas, o como un concepto dinámico, cuyo contenido evoluciona con el progreso social y económico de un país dado ${ }^{27}$.

El derecho al trabajo como derecho fundamental posee un hondo contenido ético, social y jurídico y asociado a él, se encuentra el trabajo digno que nace ligado a la dignidad ${ }^{28}$ del ser

21 Vid. Artículo 42 de la Constitución de la República de Cuba.

22 Vid. Artículo 13 inciso d) de la Constitución de la República de Cuba.

23 Vid. Artículo 45 de la Constitución de la República de Cuba.

${ }^{24}$ Vid. Título IV: Derechos, Deberes y Garantías; Capítulo III: Derechos Sociales, Económicos y Culturales; Artículo 64 de la Constitución de la República de Cuba.

${ }^{25}$ A pesar de que es con esta terminología que se reconoce a este derecho en la Constitución, consideramos que debe denominarse trabajo digno, pues es este término más abarcador, con él se hace alusión no solo a los trabajadores subordinados, sino que también incluye a los trabajadores por cuenta propia; y es por ello que en lo adelante así lo denominaremos en la presente investigación.

${ }^{26}$ Vid. Objetivo No.8 de los Objetivos de Desarrollo Sostenible, el cual se establece: Promover el crecimiento económico sostenido, inclusivo y sostenible, el empleo pleno y productivo y el trabajo decente para todos.

27 Vid. ERMIDA URIARTE, Oscar: "Trabajo decente y formación profesional”; Boletín Cinterfor No. 151; S/F; p.1.

${ }^{28}$ La noción de la dignidad se encuentra reconocida en la Constitución de la República; desde el preámbulo se declara la voluntad de que la ley de leyes, esté presidida por el profundo anhelo logrado de José Martí de que “... la ley primera de nuestra República sea el culto de los cubanos a la dignidad plena del hombre ", en el Artículo 13 inciso f) se observa como uno de los fines esenciales del Estado es garantizar la dignidad plena de las personas y su desarrollo integral y en el Artículo 40 se regula que esta constituye el valor supremo que sustenta el reconocimiento y el ejercicio de los deberes consagrados en ella, los tratados y las leyes. . 
humano, al hacer referencia al valor inherente del ser humano en cuanto ser racional, ella implica ver a los trabajadores como sujetos creadores y no como meros portadores de mercancías. Es por ello que puede afirmarse tal como reconoce el profesor MARTín SÁNCHEZ $^{29}$, que este derecho nace ligado y se complementa con el derecho a la dignidad del trabajador, pues esta dignificación se refiere, no solo a su reconocimiento como persona, sino a su mejoramiento intelectual y material.

El trabajo digno es entendido como aquel que se realiza en condiciones propicias que garanticen al trabajador la satisfacción más plena posible de todos sus derechos, enunciados de manera exhaustiva en el derecho internacional de los derechos humanos. Un criterio relevante para determinar que el trabajo no es digno es la explotación a la que se ven sometidas las personas en su trabajo y que, generalmente, está relacionada con elementos básicos del derecho como la prohibición del trabajo forzoso, la no discriminación en todos los niveles de empleo, la capacitación, la remuneración, la seguridad y la salubridad, entre otros aspectos ${ }^{30}$.

La noción de trabajo decente utilizada, tuvo su origen en la Memoria del Director General a la 87. a reunión de la Conferencia Internacional del Trabajo, celebrada en 1999, donde el Ex Director del Instituto de Investigaciones de las Naciones Unidas para el Desarrollo Social Juan Somavía, expresó que la finalidad primordial de la Organización Internacional del Trabajo (OIT) era “...promover oportunidades para que los hombres y las mujeres puedan conseguir un trabajo decente y productivo en condiciones de libertad, equidad, seguridad y dignidad humana". Este término fue introducido como respuesta al deterioro de los derechos de los trabajadores que se registró en la década del noventa del siglo pasado como consecuencia de los fenómenos de la globalización, flexibilización y desregularización laborales, los que dieron lugar a empleos ${ }^{31}$ insuficientes y de mala calidad, una protección social inadecuada, la delegación de los derechos en el trabajo y un diálogo social débil.

\footnotetext{
${ }^{29}$ Cfr. MARTín SÁNCHEZ, Antonio Raudilio: “Derechos laborales y derechos humanos”; Revista Temas No. 59; julio- septiembre de 2009; p. 76.

${ }^{30}$ Cfr. Molina Higuera, Angélica: "Contenido y alcance del derecho individual al trabajo. Marco para la evaluación de la política pública del derecho al trabajo desde una perspectiva de derechos humanos"; Defensoría del Pueblo; Colombia; 2005; p.15.

${ }^{31} \mathrm{El}$ empleo abarca todas las clases de trabajo y tiene facetas cuantitativas y cualitativas. Así pues, la idea de «trabajo decente» es válida tanto para los trabajadores de la economía regular como para los trabajadores asalariados de la economía informal, los trabajadores autónomos (independientes) y los que trabajan a domicilio. La idea incluye la existencia de empleos suficientes (posibilidades de trabajar), la remuneración (en metálico y en especie), la seguridad en el trabajo y las condiciones laborales salubres. La seguridad social y la seguridad de ingresos también son elementos esenciales, aun cuando dependan de la capacidad y del nivel de desarrollo de cada sociedad. Los otros dos componentes tienen por objeto reforzar las relaciones sociales de los trabajadores: los derechos fundamentales del trabajo (libertad de sindicación y erradicación de la discriminación laboral, del trabajo forzoso y del trabajo infantil) y el diálogo social, en el que los trabajadores ejercen el derecho a exponer sus opiniones, defender sus intereses y entablar negociaciones con los empleadores y con las autoridades sobre los asuntos relacionados con la actividad laboral. Cfr. GHAI, Dharam: Trabajo Decente. Concepto e Indicadores; Revista Internacional del Trabajo; Vol. 122; núm. 2; 2003; p.1.
} 
De esa noción de trabajo decente se destacan cuatro pilares fundamentales (los principios y derechos fundamentales en el trabajo; promoción del empleo; protección social; y diálogo social), que si se cumplen permitirán a cualquier persona acceder a un trabajo de manera digna y decente según las políticas y reglas definidas por cada nación.

Sintetiza el trabajo decente las aspiraciones de las personas durante su vida laboral. Significa la oportunidad de acceder a un empleo productivo que genere un ingreso justo, la seguridad en el lugar de trabajo y la protección social para las familias. También engloba mejores perspectivas de desarrollo personal e integración social, libertad para que los individuos expresen sus opiniones, se organicen y participen en las decisiones que afectan sus vidas, y la igualdad de oportunidades ( a partir de la existencia del empleo) y trato para todos, mujeres y hombres. ${ }^{32}$

El trabajo digno solo puede existir en condiciones de dignidad y libertad, de ello se deriva que con él se logre fomentar la inclusión y la diversidad. La promoción del trabajo digno debe hacerse para todas personas, independientemente de su orientación sexual o su identidad de género. Por ello se tiene que luchar contra toda forma de estigmatización y discriminación hacia las personas transexuales, ya que acciones prejuiciosas inciden negativamente en la obtención y mantenimiento del empleo, y ello se logra en primer lugar reconociendo que la homofobia y la transfobia fomentan la discriminación.

\section{Situaciones que afrontan las personas transexuales que le impiden acceder a un trabajo digno}

Las personas LGBT enfrentan situaciones de discriminación en el trabajo a causa de su orientación sexual e identidad de género. La discriminación y el acoso comienzan en la etapa de escolarización, reduciendo de esta manera las perspectivas de empleo. Posteriormente, la discriminación continúa en el acceso al empleo y en el ciclo de empleo; en casos extremos, los trabajadores y las trabajadoras LGBT pueden llegar a sufrir hostigamiento, acoso, abuso sexual

o maltrato físico.

A menudo, la causa de discriminación, acoso y exclusión del mercado laboral es la percepción de no conformidad con la heteronormatividad (la creencia social de que lo "normal" es ser heterosexual), y también de las ideas preconcebidas sobre la apariencia y el comportamiento que supuestamente han de tener una mujer y un hombre.

Las personas transexuales son las que enfrentan las formas más severas de discriminación laboral. Muchas son rechazadas en la entrevista de trabajo debido a su apariencia. Entre los

32 Vid. Fernández Bolaños, Masiel: "Más trabajo decente, crecimiento económico fuerte"; Seminario Internacional Orbe No. 21; Prensa Latina Agencia Informativa Latinoamericana S.A; Semana del 28 de octubre al 3 de noviembre de 2018; p.6. 
problemas que enfrentan en el lugar de trabajo, cabe citar la imposibilidad de obtener un documento de identidad donde se rectifique el sexo en el acta de nacimiento y se le cambie el nombre, la reticencia de los empleadores a aceptar su forma de vestir; la disuasión de utilizar baños acordes con su género; y una mayor vulnerabilidad al hostigamiento y el acoso por parte de sus compañeros y compañeras de trabajo. En muchos casos, los trabajadores y las trabajadoras transexuales (en particular, las mujeres trans) se ven completamente excluidos/as del empleo formal. Por ello, en algunos países, la única estrategia de supervivencia que les queda es el trabajo sexual, frecuentemente en condiciones peligrosas.

Es en relación con lo anterior y para dar cumplimiento al objetivo de esta investigación que nos adentraremos a analizar los principales factores jurídicos, de política y cotidianos que obstaculizan que las personas transexuales puedan acceder a un trabajo digno en Cuba y lo haremos desde los propios elementos que forman el contenido de dicho concepto.

\section{Indicadores del trabajo digno}

\subsection{La faceta de los derechos fundamentales}

\section{La discriminación en el trabajo}

La discriminación en el trabajo consiste en denegar la igualdad de trato y de oportunidades a las personas, por ellas mismas o por pertenecer a un colectivo social determinado. Se reconoce tanto en la Constitución como en el Código de Trabajo, la igualdad de todos las personas ${ }^{33}$ y en este sentido todos los que tengan capacidad para trabajar son los que tienen derecho al trabajo como derecho fundamental; y en Cuba, la titularidad del derecho como se preceptúa en el artículo 31 de la Constitución, la va a tener todas las personas.

El derecho a obtener un trabajo digno se dificulta para las personas transexuales, en primer lugar, por la propia regulación del anterior texto constitucional ${ }^{34}$ y en la norma laboral vigente del principio de no discriminación ${ }^{35}$,pues aunque la orientación sexual en ellos se entiende como un motivo discriminatorio prohibido, se obvia dentro de su formulación la identidad de género, siendo ello una omisión importante toda vez que niega protección jurídica ante eventos discriminatorios a estas personas cuyos derechos se pueden encontrar lesionados en ese ámbito ${ }^{36}$; sin embargo esta dificultad encuentra solución en el artículo 42 de la Constitución, donde se incluye como contenido del derecho la no discriminación a la identidad de género.

\footnotetext{
${ }^{33}$ Vid. Artículos 42 de la Constitución de la República y Artículo 2 inciso b) del Código de Trabajo.

${ }^{34}$ Vid. Artículo 42 de la Constitución de la República de 1976.

${ }^{35}$ Vid. Artículo 2 inciso b) in fine del Código de Trabajo.

36 Vid. VÁzQuez SeIJIDO, Manuel: “Derechos Sexuales ...”; Ob. cit, p. 352.
} 


\section{La libertad de sindicación}

La libertad de asociación es un derecho humano fundamental relativo a derechos de los trabajadores y los empleadores a constituir sus propias organizaciones independientes para defender sus intereses, organizar actividades conjuntas y participar en negociaciones y conversaciones referentes a esos intereses. Los trabajadores transexuales en el país tienen el derecho de asociarse, y de formar parte de la membresía de los sindicatos que se encuentren constituidos en cada uno de los centros laborales del país. Tiene reconocimiento legal en los artículos 56 de la Constitución de la República, y en el 2 inciso j) del Código de Trabajo.

\section{La negociación colectiva}

Se da entre los sindicatos y las organizaciones de empleadores, en la empresa o en el ámbito del sector o de todo el país, tanto si la empresa es de carácter privado, como si es estatal o es una cooperativa.

En algunos centros laborales del país lo relativo a las personas transgéneros no constituye un tema de preocupación, pues se trata de un grupo minoritario, o sencillamente inexistente. Si en el ámbito laboral cubano el sindicato ${ }^{37}$ es la organización o asociación que representa a todos los trabajadores constituido para la defensa y promoción de intereses profesionales, económicos o sociales de sus miembros y el colectivo de trabajadores, el apoyo de las organizaciones de trabajadores debe contribuir a la defensa de los intereses de las personas transexuales y un medio propicio para ello sería el reconocimiento de cláusulas en los Convenios Colectivos de Trabajo ${ }^{38}$ sobre el derecho de las personas transexuales a obtener un trabajo digno, la prohibición de toda forma de discriminación hacia ellos por su identidad de género y la promoción de sus derechos en el lugar de trabajo.

\subsection{La faceta del empleo}

\section{Oportunidad de empleabilidad y empleo}

Para medir las oportunidades de empleo se han utilizado tradicionalmente varios indicadores y los tres más corrientes son la tasa de actividad (población integrada en la fuerza de trabajo), la tasa de empleo (también llamada tasa de ocupación, -relación entre la población ocupada y la población en edad de trabajar-; ofrece la ventaja de dar información acerca de la cantidad y el porcentaje de personas en edad laboral que se dedican a producir bienes y servicios y sobre su desglose por edad y sexo.); y la tasa de desempleo- se considera desempleado a quien no tiene empleo, pero está disponible para trabajar y busca activamente trabajo ${ }^{39}$.

\footnotetext{
${ }^{37}$ Vid. Capítulo II: Organizaciones Sindicales, del Código de Trabajo

38 Vid. Capítulo XIV: Convenios Colectivos de Trabajo, del Código de Trabajo

${ }^{39}$ Cfr. GHAI, Dharam: "Trabajo Decente. Concepto e Indicadores"; Revista Internacional del Trabajo; Vol. 122; núm. 2; 2003; p.6. Ley del Registro del Estado Civil, Ley No. 51 de 15 de julio de 1985.
} 
Es en el momento de selección en el que la persona encargada del contrato puede comenzar a descubrir la particularidad del trans a partir del conocimiento de sus datos personales. Se percibe mayoritariamente en el caso de aquellos que no tengan terminado el cambio de identidad de género en el registro civil, (en el caso de Cuba es el Registro del Estado Civil la institución de carácter público, a través de la cual el Estado garantiza la inscripción de los hechos y actos relacionados con el estado civil de las personas $)^{40}$; al no coincidir el sexo indicado en la documentación aportada, con los aspectos exteriores de la persona trans. Ello conlleva a la discriminación mediante conductas transfóbicas o la utilización de comentarios que atentan contra la dignidad de estas personas, o simplemente con excusas que justifican la no superación del proceso de selección ${ }^{41}$.

Vulneran y disminuyen la oportunidad de empleo a las personas trans, acciones ${ }^{42}$ como: el no contratarlas para un determinado puesto por la falta de "correspondencia" entre la expresión de género (es decir, su indumentaria, sus maneras o su voz) y el género legal reconocido en el carné de identidad al no tener hecho aún el cambio de nombre, ni de sexo y entrar en contradicción con la imagen que proyectan, siendo a veces las personas más idóneas para ocuparlo; el encasillarlas como aptos para ciertas ocupaciones y no para otras en el caso del sector de la Salud Pública a estas personas se les contrata solamente para desempeñar labores de limpieza-; y los despidos injustificados o de denegación de promociones.

\section{El empleo remunerador}

Una característica importante del trabajo decente es que los trabajadores disfruten de un empleo «remunerador», que es un elemento de la «calidad» del trabajo ${ }^{43}$. Sin embargo, muchas personas transexuales se apartan ante situaciones de discriminación por completo del empleo formal, y optan por el trabajo independiente o informal.

\footnotetext{
${ }^{40}$ Vid. Artículos 2, 3 y 47 de la

41 Vid. AlmeIDA SuÁREZ, Marislienis: "Influencia del ámbito laboral en los procesos de integración desintegración social de las personas transexuales en Cuba"; Trabajo de Diploma; Universidad Central Marta Abreu de las Villas; 2014; p. 34

42 Hace alusión el especialista del Centro Nacional de Educación Sexual Andy Aquino en su Artículo "La relación prostitución- empleo: Imaginario social de las personas trans en Cuba", a la Encuesta sobre indicadores de prevención e infección por VIH/sida- 2013. Resultados del estudio Representación social de las personas en Cuba: actitudes de la población hacia ellas, de la Oficina Nacional de Estadística e Información relativo a las principales situaciones u opiniones en que se manifiestan actitudes discriminatorias hacia las personas trans, por sexo en el ámbito laboral y destacándose: el considerar que una persona travesti o transexual no pudiera desempeñar cualquier trabajo; el no permitir que una persona travesti o transexual fuera su compañero de trabajo, el no admitir atenderse en los servicios de salud, y recibir servicios generales por una persona que conozca que es travesti o transexual; el no permitir a una persona trans que vaya vestida a su centro de trabajo con ropa acorde al sexo con que se identifica, ni que sean llamadas por el nombre que más cómodo le resulte. Vid. AQuiNo AGÜERO, Andy: "La relación prostitución- empleo...”; Ob. cit; pp 192-193.
}

${ }^{43}$ Vid. GHAI, Dharam: “Trabajo Decente...”; Ob. cit; p. 8. 
Ante la imposibilidad de acceder a un empleo y de poder satisfacer con el salario ${ }^{44}$ sus necesidades, se concibe como solución por personas trans la prostitución como "el trabajo que les toca hacer". En el país la prostitución de las personas transexuales es muy barata, pues el servicio prestado se ha despreciado por diferentes causas como: el hecho de ser trans implica menos dinero por concepto de pago y la cantidad significativa de personas trans de todo el país prostituyéndose en La Habana, lo que implica que no se llegue a un consenso de dinero por prestaciones ofrecidas ${ }^{45}$. Desde la nueva norma constitucional que reconoce en el Artículo 31 al trabajo remunerado como la fuente principal de ingresos, se tributará que las personas transexuales tengan condiciones de vida dignas, pues ello permite elevar su bienestar material y espiritual, así como la realización de los proyectos individuales, colectivos y sociales.

\subsection{La faceta de la seguridad y protección social.}

La seguridad y protección social son una necesidad pues mediante ellas se pretende que, al cesar la actividad laboral, todas las personas tengan la posibilidad de continuar con una vida digna y decente como recompensa a los años de trabajo.

La seguridad social sirve para atender las necesidades de subsistencia apremiantes de la población y ampararla frente a los imprevistos; por consiguiente, es un aspecto importante del trabajo decente, tiene por objeto proteger a los trabajadores de riesgos y circunstancias como el desempleo, la enfermedad, la maternidad, la incapacidad y la miseria en la vejez ${ }^{46}$.

La protección social guarda relación con el matrimonio igualitario y las uniones civiles, ya que el reconocimiento formal de las relaciones de los trabajadores y las trabajadoras transexuales y de sus parejas e hijos le confiere el derecho a asistencia médica, pensiones, derechos de adopción, licencia parental, y prestaciones en las mismas condiciones que a las parejas heterosexuales. En Cuba el no reconocimiento en la Constitución del matrimonio igualitario es uno de los aspectos que impide que en el ámbito laboral las personas transexuales puedan acceder de una forma plena a la seguridad y protección social ${ }^{47}$, pues se dan casos donde al no tener la condición de cónyuge no pueden acceder a esa protección.

El acceso a servicios de salud provistos a través del empleo constituye un problema para muchos, pues por el temor a la estigmatización, se abstienen de hacer uso de servicios de prevención, tratamiento y asistencia necesarios y fundamentales, por no poder ingresar en las salas que más cómodo le resulta de acuerdo con el sexo con el que se identifica.

\footnotetext{
${ }^{44}$ Vid. Artículo 109 del Código de Trabajo donde se regula que es salario la remuneración en dinero que el empleador paga al trabajador atendiendo a la cálida y cantidad de trabajo realizado y al tiempo real laborado, según corresponda.

${ }^{45}$ Vid. AQUino AGÜERo, Andy: “La relación prostitución- empleo...”; Ob. cit; p. 200.

${ }^{46}$ Vid. GHAI, Dharam: "Trabajo Decente...”; Ob. cit; pp. 12-13.

${ }^{47}$ Cfr. Artículo 2 inciso h) de la Ley No. 116 Código de Trabajo.
} 


\subsection{La faceta del diálogo social}

El diálogo social de los diferentes colectivos sociales y económicos, y entre ellos y las autoridades públicas, es un atributo esencial de la sociedad democrática y un instrumento para resolver con espíritu de concordia los conflictos de intereses que inevitablemente surgen a propósito de las políticas económicas y sociales ${ }^{48}$.

El diálogo entre el gobierno y las organizaciones de empleadores y de trabajadores es un factor decisivo para lograr los objetivos de la OIT relativos a la promoción de oportunidades de trabajo decente y productivo para mujeres y hombres, en condiciones de libertad, igualdad, seguridad y dignidad humana; y el derecho a la libertad de sindicación está estrechamente relacionado con este pilar.

Para la mayoría de los agentes económicos, el diálogo social más cercano es el que sucede en su entorno laboral inmediato: entre los trabajadores mismos y entre las asociaciones que los representan y los representantes de los grupos para quienes trabajan. En Cuba cuando el derecho de las personas transgéneros a obtener un trabajo digno se vea limitado, deben existir distintas vías para lograr su inserción no solo social , sino también laboral, una de ellas es el desarrollo de políticas públicas ${ }^{49}$, especialmente políticas de empleo inclusivas, pues mediante ellas se darán respuestas a sus necesidades, intereses y aspiraciones en este ámbito y se generarán las condiciones para el diálogo social tripartito, en defensa de sus derechos. Las negociaciones colectivas deben constituir otra de las vías para su materialización, pero ello dependerá de una correcta articulación, pues no basta la voluntad que se encuentra plasmada en la Constitución de la República.

\section{Conclusiones}

- Con la presente investigación se pudo constatar como la transexualidad, ha roto los estereotipos hegemónicos del binarismo de género, pero a pesar de la inserción de las personas transexuales en diferentes espacios de la vida social, se observan situaciones de exclusión, discriminación y desintegración.

- El ámbito laboral es uno de ellos, a pesar que es mediante el trabajo donde los trabajadores pueden satisfacer tanto sus necesidades personales como las de sus familiares, y para ello cuentan con el derecho a trabajar, en tanto este constituye, un derecho humano y fundamental a través del cual esas necesidades pueden ser satisfechas.

\footnotetext{
${ }^{48}$ Vid. GHAI, Dharam: “Trabajo Decente...”; Ob. cit; p. 22.

${ }^{49}$ Pues al Estado le corresponde crear las condiciones para garantizar la igualdad de sus ciudadanos y un medio para hacer efectivo este derecho es la implementación de políticas públicas y leyes para potenciar la inclusión social y la salvaguarda de los derechos de las personas cuya condición lo requieran. Vid Artículo 44 de la Constitución de la República.
} 
- Al reconocerse en la nueva Constitución de la República de Cuba, el principio de igualdad de todas las personas, en virtud del cual gozan de los mismos derechos y la prohibición de cualquier forma de discriminación lesiva a la dignidad, dentro de las que se incluye la identidad de género; y el derecho a obtener un trabajo digno, las personas transexuales en Cuba no deben presentar en ningún caso, dificultades para obtener o mantener un trabajo digno, por no cumplirse o cumplirse de manera inadecuada con los indicadores que integran dicho derecho, a saber: los principios y derechos fundamentales en el trabajo; la promoción del empleo; la protección social; y el diálogo social, toda vez que con ello se atentaría contra el principio de supremacía constitucional, que implica el cumplimiento inexcusable por todos de los postulados y regulaciones contenidos en la norma de mayor jerarquía.

\section{Referencias bibliográficas.}

ALMEIDA SUÁREZ, Marislienis: "Influencia del ámbito laboral en los procesos de integración - desintegración social de las personas transexuales en Cuba"; Trabajo de Diploma; Universidad Central Marta Abreu de Las Villas; 2014.

AQUINO AGÜERO, ANDY: "La relación prostitución- empleo: imaginario social de las personas trans en Cuba"; en ALFONSO RODRÍGUEZ, Ada C. y CASTRO ESPÍN, Mariela. (Compiladoras): "Violencia de Género, prostitución y trata de personas"; Editorial CENESEX; La Habana; 2017.

BATISTA TORRES, Jennifer: "El derecho al trabajo en el marco constitucional cubano"; Tesis en opción al título de Máster en Derecho Constitucional y Administrativo; Facultad de Derecho de la Universidad de la Habana, Departamento de Estudios Jurídicos Básicos; La Habana; 2018

CASTRO ESPÍN, Mariela: "Estrategia para la integración social de las personas transexuales en el contexto actual de la sociedad cubana."; Tesis en opción al Grado Científico de Doctora en Ciencias Sociológicas; Facultad de Filosofía e Historia, Departamento de Sociología; Universidad de la Habana; La Habana; 2014.

CASTRO ESPÍN, Mariela. (Compiladora): "La transexualidad en Cuba"; Editorial CENESEX; La Habana; 2008.

ERMIDA URIARTE, Oscar: "Trabajo decente y formación profesional"; Boletín Cinterfor No. 151; S/F.

FERNÁNDEZ BOLAÑOS, Masiel: "Más trabajo decente, crecimiento económico fuerte"; Seminario Internacional Orbe No. 21; Prensa Latina Agencia Informativa Latinoamericana S.A; Semana del 28 de octubre al 3 de noviembre de 2018 
GHAI, Dharam: Trabajo Decente. Concepto e Indicadores; Revista Internacional del Trabajo; Vol. 122; núm. 2; 2003

GUERRA GUERRA, G. I: "Representación social de la sexualidad en un grupo de transexuales de Ciudad de La Habana"; en ROMERO ALMODÓVAR, M. y. ECHEVERRÍA LEÓN, D. (Compiladores): "Convergencias en género: apuntes desde la sociología”; Editorial Juan Marinello, La Habana, 2010.

HERNÁNDEZ DE ARMAS, Yosbel y RIVERO PINO, Ramón: “Acompañando la construcción de proyectos de vida de personas trans que practican el sexo transaccional en Cuba"; en ALFONSO RODRÍGUEZ, Ada C. y CASTRO ESPÍN, Mariela. (Compiladoras): "Violencia de Género, prostitución y trata de personas"; Editorial CENESEX; La Habana; 2017.

MARTÍN SÁNCHEZ, Antonio Raudilio: "Derechos laborales y derechos humanos"; Revista Temas No. 59; S/L, julio- septiembre de 2009.

MOLINA HIGUERA, Angélica: "Aproximaciones sobre el derecho al trabajo desde la perspectiva de los derechos humanos"; Estud. Socio-Juríd.; No.9; Bogotá, Colombia; abril de 2007.

MOLINA HIGUERA, Angélica: "Contenido y alcance del derecho individual al trabajo. Marco para la evaluación de la política pública del derecho al trabajo desde una perspectiva de derechos humanos"; Defensoría del Pueblo; Colombia; 2005

SIEGEL, Richard: "Hacia la formulación de una observación general sobre el derecho a trabajar: elementos básicos"; Documento informativo presentado al Comité de Derechos Económicos, Sociales y Culturales el día de debate general sobre el artículo 6 del Pacto, 24 de noviembre de 2003.

VÁZQUEZ SEIJIDO, Manuel: "Derechos Sexuales y violencia de género: algunas aproximaciones a la problemática de la violencia hacia las personas LGBTI en Cuba"; en ALFONSO RODRÍGUEZ, Ada C. y CASTRO ESPÍN, Mariela. (Compiladoras): "Violencia de Género, prostitución y trata de personas"; Editorial CENESEX; La Habana; 2017.

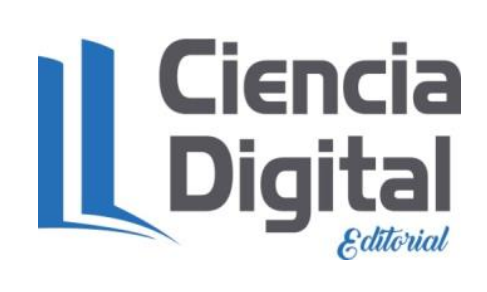


Para citar el artículo indexado.

Portuondo del Pino, D., \& Lam Peña, R. (2019). El empleo digno de las personas transexuales en Cuba. Análisis a la luz de la nueva Constitución de la República de Cuba. ConcienciaDigital, 2(4), 27-42. https://doi.org/10.33262/concienciadigital.v2i4.850

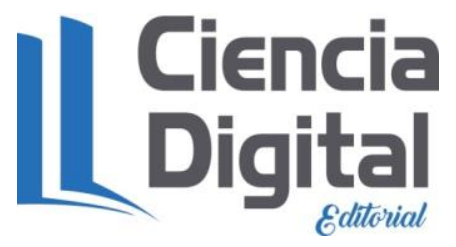

El artículo que se publica es de exclusiva responsabilidad de los autores y no necesariamente reflejan el pensamiento de la Revista Ciencia Digital.

El articulo queda en propiedad de la revista y, por tanto, su publicación parcial y/o total en otro medio tiene que ser autorizado por el director de la Revista Ciencia Digital.
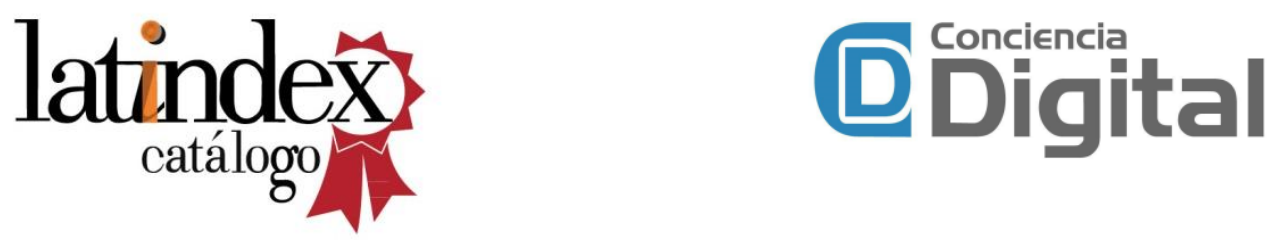